\title{
SOCCER AND STOCK MARKET RISK: EMPIRICAL EVIDENCE FROM THE ISTANBUL STOCK EXCHANGE ${ }^{1,2,3}$
}

\section{HAKAN BERUMENT}

\author{
Department of Economics
} Bilkent University

\section{NILDAG BASAK CEYLAN}

Department of Banking and Finance Yildirim Beyazit University

Summary.-There is an emerging but important literature on the effects of sport events such as soccer on stock market returns. After a soccer team's win, agents discount future events more favorably and increase risk tolerance. Similarly, after a loss, risk tolerance decreases. This paper directly assesses risk tolerance after a sports event by using daily data from the three major soccer teams in Turkey (Beşiktaş, Fenerbahçe and Galatasaray). Results provide evidence that risk tolerance increases after a win, but similar patterns were not found after a loss.

The basic assumption of economic theory is that economic agents are rational decision makers. However, behavioral economics challenges this assumption and incorporates the role of emotions in decision making (see Stracca, 2004). Economic agents may weigh objective probabilities subjectively under uncertainty and thus, the probability weighting function may depend on agents' emotional states (see Loewenstein, 2000; Romer, 2000; Loewenstein, Weber, Hsee, \& Welch, 2001). Mood, feelings, and emotions play a role in decision making and forming judgments on the weighting function. For example, Schwarz (1990) and Loewenstein, et al. (2001) linked changes in mood (visceral factors like anger and fear) and feeling (like pain and anger) to decision making, while Etzioni (1988), Romer (2000), and Hanoch (2002) elaborated on the importance of emotions in economic decision making, such as normative commitments and effective involvements, like royalty and commitments to a person or group.

Mood changes are a source of irrationality (see Berument \& Ceylan, 2012). Edmans, Garcia, and Norli (2007) and Berument, Ceylan, and Gozpinar (2006) examine how the outcomes of international soccer matches affect stock market returns. The current study is an examination of the effects of international soccer matches on stock market risks to assess risk tolerance after controlling for their role in stock market returns. To be particular, it was hypothesized that the conditional variance of the stock market, as a measure of market risk, increases after a win and decreases after a loss by a major team.

\footnotetext{
${ }^{1}$ Address correspondence to Nildag Basak Ceylan, Department of Banking and Finance, Yildirim Beyazit University, 06690, Ankara, Turkey or e-mail (nbceylan@ybu.edu.tr).

${ }^{2}$ The authors thank Rana Nelson for her helpful suggestions.

${ }^{3}$ The name of the sport is soccer in North America, but football in most of the rest of the world.
} 


\section{METHOD}

The main focus of this paper is to examine how soccer scores affect stock market risk. Following Engle (2002), in general, and Berument, et al. (2006) in their application on soccer, a conditional variance specification was employed such that conditional variance is taken as a measure of market risk, and consider the following model:

$$
\begin{aligned}
& R_{t}=x_{t}^{\prime} \beta+\phi \text { outcome }_{t}+\lambda h_{t}+\varepsilon_{t} \\
& \quad \varepsilon_{t} \sim\left(0, h_{t}^{2}\right) \\
& \log h_{t}^{2}=\kappa+\sum_{i=1}^{p} \delta_{i} \log h_{t-i}^{2}+\sum_{j=1}^{q} \gamma_{j}\left(\left|\frac{\varepsilon_{t-j}}{h_{t-j}}\right|-E\left|\frac{\varepsilon_{t-j}}{h_{t-j}}\right|+\chi \frac{\varepsilon_{t-j}}{h_{t-j}}\right)+\varphi \text { outcome }_{t},
\end{aligned}
$$

where $R_{t}$ is the stock market return calculated by taking the logarithmic first difference of the closing price of the stock market index and $x_{t}^{\prime}$ is the vector for the exogenous variables at time $t$. The vector includes daily dummies for Monday, Tuesday, Wednesday, Thursday, and Friday to account for the day-of-the-week effect, lagged dependent variables to capture the persistency (autocorrelation) of the return equation, and two dummy variables for 05.April.1994 and 21.February.2001 to account for the peak days of the financial crises that occurred in Turkey during the sample. ${ }^{4}$ Outcome $_{\mathrm{t}}$ is the dummy variable for wins and losses. Outcome takes the value of one for the next business day after a win or a loss in international matches, and zero otherwise. Also, in Equations 1 and 2, $h_{t}$ is the risk measured, captured by using Equation 2 and $\varepsilon_{t}$ is the error term at time $t$.

Equation 2 specifies the risk equation, $h_{t}^{2}$. The $\chi$ parameter allows us to capture the asymmetric effect of the error term. Outcome $e_{t}$ is entered to the risk specification here to capture soccer outcomes; the estimated parameter of Outcome $e_{t}$ is expected to capture the change in risk tolerance after wins or losses. In this paper, Outcome is used as a measure of mood; the estimated parameter is expected to be positive after a win (a measure of positive mood) and negative after a loss (a measure of negative mood).

To assess the effects of soccer events on stock market returns, daily data were gathered from Turkey, using the outcomes of Turkey's most suc-

\footnotetext{
${ }^{4}$ Turkey experienced financial crises in 1994 and 2001. In 1994, the government tried to decrease the high interest rates (due to a high budget deficit) by providing higher liquidity. However, this liquidity resulted in increased demand for foreign exchange rather than lower interest rates, and that demand could only be halted by offering a $400 \%$ return on treasury bonds. As a result, the Turkish Lira (TL) depreciated by more than half of its value, the central bank lost half its reserves, and inflation increased to three-digit levels. In 2000, the government adopted an ill-prepared exchange-rate-based disinflation program and, as a result, toward the end of 2001, government deficit exceeded the planned level and the short-term interest rate (funding rate) began to surpass the long-term interest rates offered at the beginning of 2000. As a result, a set of banks became insolvent, the central bank lost five billion dollars of its reserves in one day, inflation rate rose from $30 \%$ to $70 \%$, and domestic debt stocks and duty deficits became four times higher than in 2000.
} 
cessful soccer teams: Beşiktaş, Fenerbahçe, and Galatasaray. ${ }^{5}$ The dataset covers the period 03.July.1987 to 31.May.2011. ${ }^{6}$ The data for the Istanbul Stock Exchange (ISE) 100 Index were obtained from Datastream. The stock market return was calculated as the percentage change in the daily closing price of the ISE 100 Index. The data for international soccer match results were obtained from http: / / www.rsssf.com.

Soccer in Turkey has a set of characteristics that makes Turkey an important environment to assess the effect of soccer on economic and financial variables. Firstly, the term sport is mostly associated with soccer in Turkey; other sports such as basketball or wrestling place a distant second and third. Secondly, in Turkey, the most popular soccer teams are Beşiktaş, Fenerbahçe, and Galatasaray. Most Turks associate themselves with one of these teams, even if they might also support a local team. Thirdly, these teams' supporters are distributed around the country more or less evenly. As fans are not located in a specific geographical region, their teams' successes can affect the general mood of the country (see Berument, Ceylan, \& Ogut-Eker, 2009 for more detailed information). Fourthly, national championships are mostly won by these teams: for the sample time period considered, Beşiktaş won the championship six times, Fenerbahçe won seven times, and Galatasaray won 10 times., 8

'In this paper we look at the effects of three important teams' successes on the entire ISE. The shares of these teams are publicly traded on the ISE. The purpose of this paper is to examine how mood changes affect the overall performance of stock market returns, rather than examining how these teams' wins will affect their market value and then how that value will affect the performance of stock market returns. Such possibilities can be explored in another study. ${ }^{6}$ Equities for each team are available on the ISE. Correlations between each team's equity during the time period of this sample are as follows: the correlation between Beşiktaş and Fenerbahçe is $12 \%$, the correlation between Beșiktaş and Galatasaray is $15 \%$ and the correlation between Fenerbahçe and Galatasaray is 23\%. The correlation between the ISE return and each team are as follows: 19\% for Beşiktaş, 18\% for Fenerbahçe and 23\% for Galatasaray. ${ }^{7}$ In this study, we did not analyze the effect of the national team in international matches. Berument, Inamlik, and Yucel (2003) analyzed the effect of soccer success on industrial production by considering the successes of the Turkish national team as well as the successes of more local teams Beşiktaş, Fenerbahçe, and Galatasaray. Their main findings showed no statistically significant effect on production from national team matches, and they attribute various reasons to this: supporters' pride and self-esteem increase more if their local team wins than if the national team does because a local team's win boosts morale twice, fuelling both national identity and local identity. Moreover, local teams play more games than national teams, thus an average spectator may associate himself more with a local team, and the effect of local team wins / losses will be greater. Further, players on local teams remain more or less the same but players on the national team often change. Thus, individuals may associate themselves more with players of local teams, and pride and self-esteem will increase more from local teams' wins. In addition, the quality of the local teams might be considered greater because these teams can have foreign players, whereas national teams cannot. This fact decreases fans' expectations related to the national team, which therefore affects their mood/self-esteem less. ${ }^{8}$ The three teams considered are publicly traded companies on the ISE. In addition to the mood-stimulating (and equity-increasing) effect of wins, the better their standings, the more revenue international matches generate. Thus, key wins in international matches can have a real effect on share prices due to increased revenue. One may use publicly traded teams to distinguish between the real effect of winning and the psychological effect. 


\section{ResULTS}

Estimates regarding Equations 1 and 2 are reported in Table 1. The first column considers wins for Outcome and the second column considers losses for Outcome. The main aim of the paper is to test whether soccer score outcomes affect risk tolerance. In other words, we tested whether the estimated coefficient for Outcome in the conditional variance specification $\varphi$ in Equation 2 is zero. Panel B of Table 1 shows that the estimates are positive for wins and losses and that the coefficient is statistically significant if the outcome is a win.

To assess this hypothesis, the model is specified such that it already incorporates the well-established regularities in the literature. Testing (and providing supporting evidence) for these hypotheses provides a set of robustness analyses. The day-of-the-week-effect literature suggests that returns for each day of the week were different. Specifically, Monday returns were lower than Friday returns. Panel A of Table 1 provides statistics regarding tests of this hypothesis. For both outcomes (win or loss), the coefficients for Mondays were positive and for Tuesdays were negative, but their effects were not statistically significant $(p>.05)$. For Wednesdays and Thursdays, the effects were negative for both outcomes, but the effect was statistically significant $(p<.10)$ only for Thursdays for wins. For Fridays, the effects were positive. Next, we tested whether the estimated coefficients for Fridays were the same as the estimated coefficients for Mondays; the Friday returns were statistically significant higher than Monday returns.

Regarding the effect of soccer events on stock market returns, we tested whether the coefficient of the outcome in the return equation was zero. The estimated coefficients suggested that wins have positive effects and losses have negative effects on stock market returns, but these effects are not statistically significant. To assess whether risk is priced, we tested whether the estimated coefficient of the conditional variance specification in the return equation, $\lambda$, was zero for both outcomes. The estimated coefficients were positive and statistically significant for both, thus this hypothesis was also supported. The estimated coefficients for the two intercept dummies for 05.April.1994 and 21.February.2001 (Turkey's financial crises) are reported in Table 1 as Crisis ${ }_{1}$ and Crisis $_{2}$, respectively. Both crises had negative and statistically significant effects on the return for both outcomes.

To validate the specification, the estimates of the conditional variance specification were evaluated (see Panel B of Table 1). The coefficients for $\log \left(h_{t-1}\right)^{2}$ and

$$
\left(\left|\frac{\varepsilon_{t-1}}{h_{t-1}}\right|-E\left|\frac{\varepsilon_{t-1}}{h_{t-1}}\right|+\chi \frac{\varepsilon_{t-1}}{h_{t-1}}\right)
$$


TABLE 1

Effects of Soccer Match Outcomes on Stock Returns and the Return-volatility Relation

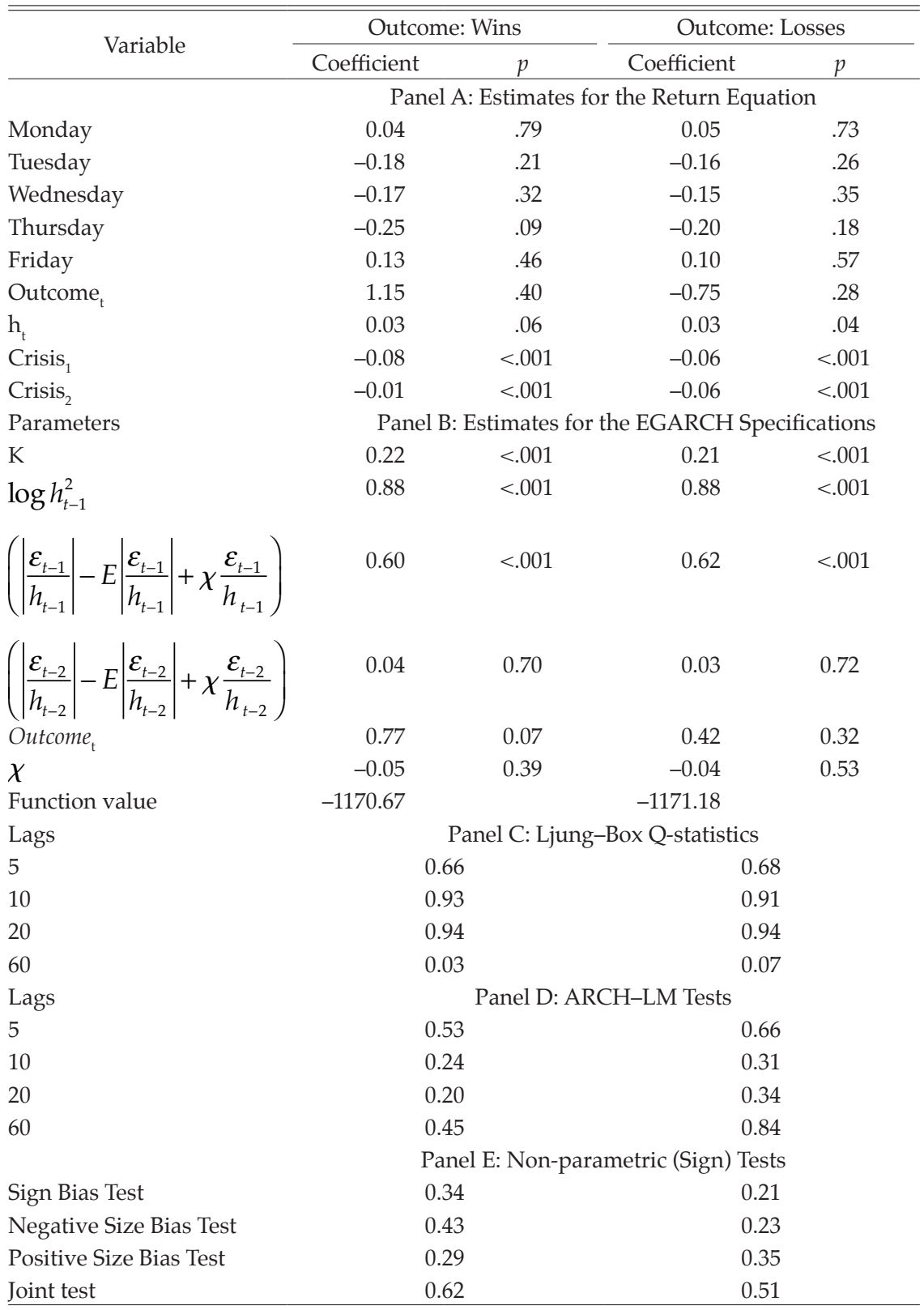

Note.-The data on soccer team scores were obtained from http:/ / www.rsssf.com and the data on returns from Datastream. To save space, the estimated coefficients for the lagged values of the dependent variable are not shown. 
were statistically significantly different from zero for both outcomes, but the second lags of the latter variable were also included although they were not statistically significant. The estimated coefficient for $\log \left(h_{t-1}\right)^{2}$ less than 1.0 satisfies the non-explosiveness of the conditional variance. Thus, the specification also satisfies this condition. The asymmetric effect, or the so-called leverage effect, suggests that negative surprises (negative $\varepsilon_{\mathrm{t}-1}$ here) increase risk more than positive surprises. In other words, the estimated coefficient for $\varepsilon_{\mathrm{t}-1}, \chi$ should be negative, likely due to an increase in a firm's debt-to-equity ratio as a result of a decrease in the firm's stock value, which may cause shareholders to feel that future cash flows are more tenuous (see Brooks, 2000).

The estimated coefficient for $\varepsilon_{t-1}, \chi$ is negative for both outcomes, which means negative surprises increase volatility more than positive ones (see Hamilton, 1994). This finding is also parallel with earlier regularities reported in the literature (see Cheung \& Ng, 1992; Kim \& Kon, 1994). However, this coefficient was statistically significant for neither wins nor losses.

Panels $C$ to E report a battery of additional specification tests. Panel C reports the Ljung-Box $\mathrm{Q}$ autocorrelation test for five, 10 and 20 lags. There was no statistically significant autocorrelation $(p>.10)$. The autocorrelation at 60 lags is too long for an autocorrelation test. Panel $\mathrm{D}$ reports the ARCH-LM heteroscedasticity test for 5, 10, 20 and 60 lags. The specifications pass autocorrelation and heteroscedasticity tests. Panel E reports a set of non-parametric tests done to assess whether there was any pattern in the sign of the residuals. Again, the specification was robust and estimates support well-established regularities noted in the financial economics literature.

\section{DISCUSSION}

The estimated coefficients of the daily dummies are in line with the findings of Balaban (1995) and Berument, et al. (2006). The positive estimated coefficient of the outcome for wins and the negative estimated coefficient of the outcome for losses in the return equation (Equation 1) are parallel to the results reported in Berument, et al. (2006) for wins and Edmans, et al. (2007) for losses. Wins may increase returns due to positive mood changes and losses decrease returns due to negative mood changes. The positive coefficients of $h_{t}$ in the return equation, parallel to the portfolio theory, suggest that agents want to be compensated for bearing a higher risk asset with higher returns and thus there is a positive relationship between risk and expected return. Moreover, the estimated coefficients of the lag values of the conditional variance and error terms in the return equation (Equation 1 ) are in line with expectations, as also reported in Hamilton (1994). Thus, the return specifications give estimates supporting the existing literature and earlier findings' validity. 
To assess the hypotheses, whether the estimated coefficients of the outcomes for wins and losses were tested against zero in the risk specification (Equation 2). There was evidence that conditional variance of the stock market return (risk measure here) increased after a win; however, there was no evidence for the opposite pattern after a loss. ${ }^{9}$ The positive and statistically significant coefficient of the outcome for wins in the risk specification suggests that risk tolerance increases only after a win.

If increased wins increase risk tolerance and decreased losses do not decrease risk tolerance, it could be argued that this situation could be exploited by "rational" investors who anticipate this "irrational" behavior. However, there are several problems with this argument: even if losses decrease risk tolerance, there is no way to observe this effect, known as a Type II error in statistics: not rejecting the null when it is false. If this effect is not present, then "rational" investors might buy an index before an international match. However, even if this profit possibility is there, it might be too small to cover the transaction cost or bid-ask spread.

\section{REFERENCES}

BALABAN, E. (1995) Day of the week effects: new evidence from an emerging market. Applied Economics Letters, 2, 139-143.

Berument, M. H., \& CEYLAN, N. B. (2012) Effects of soccer on stock markets: the returnvolatility relationship. Social Science Journal, 49, 368-374.

Berument, H., Ceylan, N. B., \& Gozpinar, E. (2006) Performance of soccer on the stock market: evidence from Turkey. Social Science Journal, 43, 695-699.

Berument, M. H., Ceylan, N. B., \& Ogut-Eker, G. (2009) Soccer, stock returns and fanaticism: evidence from Turkey. The Social Science Journal, 46, 594-600.

BRoоKs, C. (2002) Introductory econometrics for finance. Cambridge, UK: Cambridge Univer. Press.

Cheung, Y., \& NG, L. K. (1992) Stock price dynamics and firm size: an empirical investigation. Journal of Finance, 47(5), 1985-1997.

Edmans, A., GARcia, D., \& Norli, O. (2007) Sports sentiment and stock returns. Journal of Finance, 62, 1967-1998.

ENGLE, R. (2002) New frontiers for ARCH Models. Journal of Applied Econometrics, 17(5), 425-446.

EtzIONI, A. (1988) Normative-affective factors: towards a new decision-making model. Journal of Economic Psychology, 9(2), 125-150.

Hamilton, J. D. (1994) Time series analysis. Princeton, NJ: Princeton Univer. Press.

HANOCH, Y. (2002) Neither an angel nor an ant: emotion as an aid to bounded rationality. Journal of Economic Psychology, 23(1), 1-25.

KIM, D., \& Kon, S. J. (1994) Alternative models for the conditional heteroscedasticity of stock returns. The Journal of Business, 67(4), 563-598.

${ }^{9}$ Berument and Ceylan (2012) tied the magnitudes of different effects of soccer event outcomes on the stock market to success history: for countries with more-successful soccer teams, losses negatively affected the stock market, but the same effect was not found for wins. 
Loewenstein, G. (2000) Emotions in economic theory and economic behavior. American Economic Review, 90(2), 426-432.

Loewenstein, G. F., Weber, E. U., Hsee, C. K., \& Welch, N. (2001) Risk as feelings. Psychological Bulletin, 127(2), 267-286.

Romer, P. M. (2000) Thinking and feeling. American Economic Review, 90(2), 439-443.

Schwarz, N. (1990) Feelings as information: informational and motivational functions of affective states. In E. T. Higgins \& R. M. Sorrentino (Eds.), Handbook of motivation and cognition. Vol. 2. New York, NY: Guilford. Pp. 527-561.

STRACCA, L. (2004) Behavioral finance and asset prices: where do we stand? Journal of Economic Psychology, 25(3), 373-405.

Accepted April 24, 2013. 